\title{
The Relationship between Student Teachers' Perception of Intelligence and Their Goal Orientation
}

\author{
Dilek İlhan Beyaztaş ${ }^{1, *}$, Suzan Beyza Kaptı ${ }^{2}$ Barry Hymer $^{3}$ \\ ${ }^{1}$ Faculty of Education, Erzincan University, Turkey \\ ${ }^{2}$ Faculty of Education, Ankara University, Turkey \\ ${ }^{3}$ Independent Researcher, England
}

Copyright $(2017$ by authors, all rights reserved. Authors agree that this article remains permanently open access under the terms of the Creative Commons Attribution License 4.0 International License

\begin{abstract}
This study examines the views of student teachers in a Turkish university about intelligence (entity theory vs incremental theory) and goal orientation (performance goal orientation vs learning goal orientation) and the relationship between the two. Specifically, it seeks to understand whether there are any differences in participants' perceptions of intelligence and goal orientation across the 4-year (Years 1 to 4 ) teacher education programmes and across the seven disciplines (majors), and between males and females. The study includes an adaptation of the "Goal Orientation Scale", originally developed by Dweck [1], in order to measure students' goal orientation in Turkey. The study also uses the "Implicit Theory of Intelligence Scale" which was adapted into Turkish by İlhan-Beyaztaş and Hymer [2] in order to identify students' perceptions of intelligence. A group of 1409 student teachers were found to score higher on entity theory and performance goal orientation, as compared to incremental theory and learning goal orientation respectively. There also existed variations across majors, years of learning, and between genders. Positively significant relationships were found between entity theory and performance goal orientation, and between incremental theory and learning goal orientation.
\end{abstract}

Keywords Goal Orientation, Perception of Intelligence, Entity Theory, Incremental Theory, Fixed Mindsets, Growth Mindsets

\section{Introduction}

Motivation has a crucial influence on a learner's academic achievement: specifically, the extent to which a learner invests effort in her learning will be contingent on her academic motivation. The intrinsic motivation of students fosters a desire to learn based on their perceived needs, and supports their quest for meaningful learning experiences. Goal orientation is one of the most important identifiers of motivation. Goal orientation can be defined as a belief that shapes goals and behaviours before and after the learning process. The dimensions of goal orientation have been considered from different perspectives; however, the early research presented goal orientation in two dimensions as "learning orientation" and "performance orientation" [3]; [4]; [5] and these dimensions have been widely used in the field. Different labels have been used for these two classes of goal: a "performance orientation" is aligned with "ego-involved goals" [6] or "ability goals" [7], whilst having a "learning orientation" is synonymous with having "mastery goals" [7]; [8] or "task goals" [6].

Performance-oriented individuals adopt competitive behaviours, aiming to perform better than their counterparts. They tend to measure their success in relation to external factors, such as the grades and rewards they receive from their teachers. Performance-oriented individuals also aim to win positive judgments of their competence and avoid negative ones. In other words, when students pursue performance goals, they are concerned with their level of intelligence. They want to look smart (to themselves or others) and avoid looking dumb [1]. On the other hand, learning-oriented individuals focus on self-development. They tend to understand success in terms of their mastery of the specific topic or skill, or in terms of standards that they themselves set [9]. The attention of the learning-oriented learner is on finding strategies for learning. When things don't go well, this does not seem as having anything to do with the student's intellect [1]. In addition, learning-oriented individuals tend to search for ways to improve their skills and knowledge, whereas performance-oriented individuals aim to prove their skills and knowledge [10]. Moreover, the literature suggests that students' goal orientation affects their metacognition [11]; [12] their motivations, self-efficacy, task value, self-regulated learning and performance [12], and their academic achievment [13]; [14]; [11].

The Implicit Theory developed by Dweck is one of the social cognitive motivation theories which underline the relationship between learning and motivation. Dweck asserts 
that individuals may hold one of two beliefs about the nature of intelligence, and that these beliefs specify goal orientation. Some individuals believe that intelligence cannot be changed (entity theory, or fixed mindset) while others think that it can be developed (incremental theory, or growth mindset) [1].

Those who hold an entity theory (a "fixed mindset") believe that their level of intelligence is fixed at birth and that it does not significantly change along the life course: they believe that people may be able to gather more knowledge, but that their cognitive abilities will never substantially improve or worsen. Students who adopt a fixed (entity) intelligence theory focus on getting good grades in order to prove their abilities [15]; [16] because it is important for them to look smart [17]. They are performance-oriented. Performance orientation causes students not to value effort, to be easily discouraged and to avoid taking responsibility for their mistakes and difficulties [15].

Those who hold an incremental theory (a "growth mindset"), on the contrary, believe that their intelligence is not fixed and can be improved by learning [1]; [18]. Whilst not denying the role of genetics in human development, qualities such as 'talent', intelligence, etc. are seen only as the starting points for ultimate achievement. From this perspective, intelligence is fluid, changing with experience [16]. Such students focus on developing their own abilities and gaining new knowledge and skills. They are learning-oriented, and are motivated to try to learn, to seek out difficult conditions to develop learning and to persist to get over these difficulties [15]; [17].

Numerous studies suggest that the implicit theory that is adopted by students affects their achievement [13]; [19]; [15]; [20]; [1]; [4]; [21]; [10]; [22]; [23], their reactions to obstacles and difficulties [4] their motivations [19], their strategies [23] and their efforts [15]; [23].

Various research has explored the effects of students' goal orientation and their views about intelligence on their achievement. Some of the research has also investigated how these two affect each other [20]; [1]; [4]; [21]; [15]; [23]; [10]; [13]; [24]; [19]; [22]. The findings of Dweck and Leggett [4] indicated that students' learning behaviours were influenced by their perception of intelligence and their goal orientation. They also found that students who viewed intelligence as unchangeable tended to show performance-oriented behaviours. On the other hand, students who viewed intelligence as changeable tended to behave in a learning-oriented way.

Students who believe that intelligence cannot be changed tend to be performance-oriented, and this leads to them failing to make persistent efforts during learning, to giving up easily, and to denying their responsibility for mistakes. On the other hand, students who believe that intelligence can be changed or improved tend to be learning-oriented. This leads them to engage with the process of learning, improve their abilities, invest a lot of effort, and make decisions to overcome their challenges [15]. Whilst the true nature of intelligence is still in debate, how the average person constructs the concept of intelligence and how their concept impacts on their everyday behaviour is important [16].

Previous studies suggest that implicit theories about student intelligence and goal orientation are mostly related with success [13]; [19]; [15]; [20]; [1]; [4]; [21]; [410]; [22]; [23].

Teachers' choices of educational goals are related to their beliefs about the behaviours that are characteristic of intelligence, and teachers' beliefs about intelligence also affect their students' achievement [25]; [26]; [27]; [28]. Also, teachers' individual views on students' mindsets may impact their instructional approaches. Teachers who think their students have fixed intelligence are less able to support their students. In contrast, When teachers believed that intellgence is growht they provide increased support [29]. In this context, beliefs about mindset play a role in the amount of instructional support teachers offer students, which in turn is likely to have implications for student learning [30]. Although this implications are very important, studies about the effect of both existing and prospective teachers' beliefs on students' mindsets and goal orientations are, however, limited. Also, although much research has been conducted on goal orientation and perceptions of intelligence in the international arena, national studies seem to be limited in Turkey. Therefore, this study firstly uses Dweck's "Goal Orientation Survey", translated into Turkish. The study then aims to examine if there is any relationship between perception of intelligence and goal orientation in student teachers. The research aims to be the key reference study in Turkey on the study of goal orientation and the perception of intelligence.

This study proposes to answer to the following questions:

1. What is the goal orientation and perception of intelligence of university students based on their major?

2. What is the goal orientation and perception of intelligence of university students based on their level of class?

3. What is the goal orientation and perception of intelligence of university students based on their gender?

4. What is the relationship between goal orientation and perception of intelligence of university students?

\section{Materials and Methods}

In this study, the correlational research paradigm was utilized and the steps of scale adaptation recommended by Hambleton and Patsula [31] were followed.

\subsection{Study Group}

There were three study groups. The first group consisted of 524 students who were enrolled in the Faculty of Education department of Turkish Education, Primary School Education and Mathematics Education in the 2015-2016 term, with whom the "Goal Orientation" scale was adapted. The second group consisted of 100 university students, who 
completed the adapted language equivalence scales. The third group consisted of 1409 university students who were enrolled in the Faculty of Education department of Education, Primary School Education, Social sciences Education, Computer education and instructional technology, Physical Education, Science education and Mathematics Education in the 2015-2016 term, with whom the features of intelligence perceptions and goal orientation in terms of gender, class level and university departments were explored. The entire study group consists of 2033 students.

Kline [32], suggests that a sample of 200 is enough for a reliable factor pattern, but that this number can be decreased to 100 when the factor pattern is clear or low. Like Comrey [33], he also emphasizes that it is better to study with large samples. The sample sizes used in this study therefore fall within range advocated in earlier research.

\subsection{Data Collection Tools}

The study used the "Adult Version of The Implicit Theory of Intelligence Scale "which was adapted into Turkish by İlhan-Beyaztaş and Hymer [33] in order to identify students' perception of intelligence. The "Adult Version of The Implicit Theory of Intelligence Scale" is a Likert scale developed by Dweck [1] to determine the beliefs learners hold on the nature of intelligence. The original scale is a 6 point Likert-type scale ranging from "strongly agree" (1) to "strongly disagree" (6). The sub-dimensions of the scale are entity (items 1, 2, 4 and 6: "You can learn new things, but you can't really change your basic intelligence"), incremental (items 3, 5, 7 and 8: "You can change even your basic intelligence level considerably").

This study also aims to adapt the "Goal Orientation Scale", originally developed by Dweck [1] in order to measure students' goal orientation in Turkey. The scale was originally developed with four items in order to identify students' goal orientation. In the first three items, a Likert scale with six degrees was developed to measure students' opinions from "strongly agree" (1) to "strongly disagree" (6).The fourth item consists of two categories. The scale consists of two sub dimensions which are "learning goal orientation" (it's much more important for me to learn things in my classes than it is to get the best grades) and "performance goal orientation" (Although I hate to admit it, I sometimes would rather do well in a class than learn a lot).

\subsection{The Adaptation of "Goal Orientation Scale" into Turkish}

Firstly, Carol Dweck was contacted by email in order to gain her express permission to adapt the "Goal Orientation Scale" into Turkish. Then the language validity of the scale was established, as follows: the original English-language scale was translated into Turkish by four independent translators whose first language was Turkish. The translators all worked at a Turkish university: two of them were $\mathrm{PhD}$-qualified lecturers in a department of curriculum and instruction; and the others were lecturers in a department of
English Language. The translators produced four different versions of the instrument. These were revised using the Delphi technique [34]; [35]; [36] the best translations were agreed, and the first form of the scale was created. This first form was then translated into English by two independent translators working in the department of English Language and Literature. The items of the instrument were compared by translating from Turkish to English and English to Turkish. After comparisons, two other experts - one from the department of Turkish Language and Literature and the other an expert on Turkish language - evaluated the scale in terms of grammar and intelligibility.

\subsection{Reliability and Construct Validity Analysis of "Goal Orientation Scale"}

The "Goal Orientation Scale" was used with 550 students who were attending Faculty of Education, Department of Turkish Language, Elementary and Maths Education during 2015-2016, in order to test for validity and reliability. The survey questions were revised and fourth item of the survey was transformed into 6 Likert scale (If I had to make a choice between grading high score and providing high effort to learn, I would prefer providing high effort to learn) in a way that would fit the meaning of the entire survey. Reliability and assumptions were checked before conducting CFA. Croanbach's Alpha value was observed lower when applied two dimensioned scale when 4th questions with two categories. When the same scale's 4th question was applied with 6 Likert scale, the Croanbach's Alpha value regarding learning orientation was observed .81 while it was observed .61 for performance orientation. Croanbach's Alpha value has to be above .7 in order to be reliable according to Pallant [37]. However, Croanbach's Alpha value is sensitive towards the number of items in the survey. "It is commonly observed that the surveys having less items (lower than 10 items) seems to score lower." [37]. Mean inter-item correlation (MIIC) is recommended for the reliability of the items which are short or have different length [37]; [38]. Briggs and Cheek [39] state that mean inter-item correlation value should range between 0,2 and 0,4 for reliability. From this context, the study tested mean inter-item correlation. The MIIC value for performance dimension is 0,38 and it is 0,31 for learning dimension. This means that both values satisfy the ranges that Briggs and Cheek [39] specified.

CFA was conducted to examine the construct validity of the survey. CFA was run on 4 items with 6 Likert items which were specified as reliable. The research also tested whether the survey which was applied to 550 students was appropriate or not and whether the data satisfied the assumptions of CFA or not. 26 students were excluded as a result of these tests and the study continued with 524 students. The age of the participants ranged between 17 and 34. The rest of the demographic findings are presented in Table 1. 
Table.1. Descriptive Statistics for Sample used for Confirmatory Factor Analysis

\begin{tabular}{|c|c|c|c|c|c|c|}
\hline Department & Female & Male & 1. Class & 2. Class & 3. Class & 4. Class \\
\hline Elementary Education & 137 & 84 & 48 & 62 & 54 & 57 \\
\hline Mathematics Education & 102 & 40 & 35 & 39 & 36 & 32 \\
\hline Turkish Language Education & 118 & 43 & 42 & 32 & 39 & 48 \\
\hline Total & 357 & 167 & 125 & 133 & 129 & 137 \\
\hline
\end{tabular}

Table 2. Arithmetic Mean and Standard Deviation Statistics of University Students' Intelligence Perception and Goal Orientation Features According to University Department Variable

\begin{tabular}{|c|c|c|c|c|c|c|c|c|}
\hline & \multicolumn{2}{|c|}{ Entity } & \multicolumn{2}{c|}{ Incremental } & \multicolumn{2}{c|}{$\begin{array}{c}\text { Performance Goal } \\
\text { Orientation }\end{array}$} & $\begin{array}{c}\text { Learning Goal } \\
\text { Orientation }\end{array}$ \\
\hline & $\bar{x}$ & $\mathrm{df}$ & $\bar{x}$ & $\mathrm{df}$ & $\bar{x}$ & $\mathrm{df}$ & $\bar{x}$ & $\mathrm{Df}$ \\
\hline Turkish Education (N=263) & 15,71 & 5,32 & 12,63 & 4,99 & 8,01 & 2,47 & 5,17 & 2,37 \\
\hline Mathematics Education (N=187) & 15,92 & 4,87 & 11,89 & 4,41 & 7,58 & 2,35 & 5,28 & 2,42 \\
\hline Social Sciences Education (N=148) & 15,77 & 5,67 & 11,14 & 3,92 & 7,64 & 2,54 & 4,77 & 2,71 \\
\hline $\begin{array}{c}\text { Computer Education and Instructional Technology } \\
(\mathrm{N}=175)\end{array}$ & 15,92 & 4,69 & 11,39 & 4,04 & 7,42 & 2,37 & 5,66 & 2,85 \\
\hline Physical Education (N=146) & 15,17 & 4,74 & 11,39 & 4,08 & 6,79 & 2,06 & 5,41 & 1,89 \\
\hline Elementary Education (N=292) & 15,85 & 5,05 & 11,85 & 4,21 & 7,78 & 2,48 & 5,22 & 2,37 \\
\hline Science Education (N=198) & 16,84 & 4,97 & 10,92 & 4,13 & 7,29 & 2,46 & 5,20 & 2,35 \\
\hline
\end{tabular}

CFA was carried out to test construct validity. Using CFA, the following scores were obtained: scores of the chi square fit test $\left(\chi^{2}\right)$, the average root mean of the square error of approximation (RMSEA), the comparative fit index (CFI), and the square root of residual averages (RMR). In field literature, the use of the $\chi^{2} /$ sd proportion called the normalized chi-square is recommended because it is sensitive to the sample size of $\chi^{2}$; the proportion below 3 in big samples is regarded as the indicator of perfect fit, and the proportion below 5 as the indicator of medium fit [40]; [41]. RMSEA and RMR with the value below or equal to 0.05 shows a good fit, the value between 0.05 and 0.08 shows sufficient level of fit, and the value between 0.08 and 0.10 shows a medium level of fit [42]; [43]. CFI values higher than 0,95 suggests a perfect fit and a value higher than 0,90 is regarded as an acceptable value [41]. GFI and AGFI values higher than 0,95 suggests a perfect fit and a value higher than 0,90 is regarded as an acceptable value (Hooper, Coughlan and Mullen, 2008).

The fit indices calculated through CFA were found to be $\mathrm{RMSEA}=0.00, \mathrm{CFI}=1, \mathrm{GFI}=1, \mathrm{AGFI}=1$, and $\mathrm{SRMR}=$ 0.0044 . It was observed that the $\chi^{2}=0.26(\mathrm{sd}=1)$ statistics were significant $(\mathrm{p}<01)$ and it was calculated as $\chi^{2} / \mathrm{sd}=0.26$. The observed values show that the fit indices is consistent. After CFA, the linguistic equivalence was calculated. The findings on the linguistic equivalence indicated that the correlation between the items included in the Turkish and the original form varied between .78 and .91 .

\section{Results}

1409 students returned complete responses. The findings of the study are given here in relation to the sub questions.

\subsection{What is the Goal Orientation and Perception of Intelligence of University Students Based on Their Major?}

The first research problem of the study is "What are the features of intelligence perceptions and goal orientation of university students according to university department variable?" and the descriptive scores related to this question are given in Table-2.

When comparing the perception of intelligence scores in relation to university department, the entity scores are higher than the incremental scores. Also, the performance goal orientation scores are higher than the learning goal orientation scores.

Table 3 illustrates the MANOVA results which include the comparison of the scores for intelligence perception and goal orientation, grouped by university department. 
Table 3. MANOVA Results which show the Comparison of Total Scores of University Students' Intelligence Perception and Goal Orientation Features According to University Department Variable

\begin{tabular}{|c|c|c|c|c|c|}
\hline & Wilks' Lambda & F & Hypothesis df & Error df & P \\
\hline Intelligence Perception &, 974 & 3,084 & 12 & 2802 &, 00 \\
Goal Orientation &, 971 & 3,436 & 12 & 2802 &, 00 \\
\hline
\end{tabular}

Table 4. The results of Multivariate Analysis of Variance (MANOVA) for Each Perception of Intelligence and Goal Orientation in Terms of University Department

\begin{tabular}{|c|c|c|c|c|c|c|}
\hline & Type III sum of Sm & $\mathrm{df}$ & Mean Square & F & P & Difference \\
\hline Entity & 266,16 & 6 & 44,361 & 1,72 &, 111 & \\
\hline Error & 35999,02 & 1402 & 25,67 & & & \\
\hline Incremental & 436,93 & 6 & 72,82 & 3,89 &, 001 & tle-sse, tle-se \\
\hline Error & 26237,05 & 1402 & 18,71 & & & tle-se, tle-pe, me-pe, \\
sse-pe, ee-pe
\end{tabular}

Table 5. Arithmetic Mean and Standard Deviation Statistics of University Students' Intelligence Perception and Goal Orientation Features According to Class Level Variable

\begin{tabular}{|c|c|c|c|c|c|c|c|c|}
\hline & \multicolumn{2}{|c|}{ Entity } & \multicolumn{2}{|c|}{ Incremental } & \multicolumn{2}{|c|}{ PGO } & \multicolumn{2}{|c|}{ LGO } \\
\hline & $\bar{x}$ & Df & $\bar{x}$ & df & $\bar{x}$ & $\mathrm{df}$ & $\bar{x}$ & Df \\
\hline 1.Class $(\mathrm{N}=387)$ & 15,93 & 5,05 & 11,40 & 4,41 & 7,44 & 2,40 & 5,36 & 2,37 \\
\hline 2. Class $(\mathrm{N}=448)$ & 16,46 & 5,07 & 11,49 & 4,30 & 7,72 & 2,45 & 5,05 & 2,39 \\
\hline 3. Class $(\mathrm{N}=303)$ & 15,39 & 5,22 & 11,75 & 4,23 & 7,41 & 2,51 & 5,27 & 2,53 \\
\hline 4. Class $(\mathrm{N}=271)$ & 15,50 & 4,86 & 12,37 & 4,41 & 7,66 & 2,35 & 5,36 & 2,50 \\
\hline
\end{tabular}

When Table 3 is analyzed, the average scores for intelligence perception (Wilks' Lambda value, 974, F=3,084, $\mathrm{p}<.05$ ) and goal orientation (Wilks' Lambda value, 971, $\mathrm{F}=3,436, \mathrm{p}<.05)$ in terms of university department show a significant difference of ,05 level.

Table 4 illustrates the information about both about comparative scores for the entity and incremental dimensions (two of the intelligence perception dimensions) and comparative scores for performance goal orientation and learning goal orientation (two of the goal orientation dimensions) by university department.

The $\mathrm{F}$ test is included in Table 4 to compare both the mean scores for the entity and incremental dimensions and the mean scores for the performance and learning goal orientation dimensions by university departments. According to the MANOVA results, the mean scores for the incremental and performance goal orientation dimensions show a statistically significant difference in relation to university department (respectively $\mathrm{F}=3,89 \mathrm{p}<.05, \mathrm{~F}=4.95$ $\mathrm{p}<.05)$.

As the groups were not homogeneous, the Tamhane test was used in order to find out which university department-groups showed the difference in the mean scores of the incremental intelligence and performance goal orientation. According to the Tamhane results, for the incremental intelligence dimension, there is a significant difference between the Departments of Turkish Language Education and Social Sciences Education; Turkish Language
Education and Science Education - in the direction of the first-named department. For the performance goal orientation dimension, there is a significant difference between the Departments of Turkish Language Education and Science Education; Turkish Language Education and Physical education; Mathematics Education and Physical education; Social Sciences Education and Physical education; Elementary education and Physical education - in the direction of the first-named department. The differences had statistical significance.

\subsection{What is the Goal Orientation and Perception of Intelligence of University Students Based on Their Level of Class?}

The second problem of the study is "What are the features of intelligence perceptions and goal orientation of university students according to their university class level?" and the descriptive scores related to this question are given in Table-5.

When comparing the perception of intelligence scores in terms of class level, the entity scores are higher than the incremental scores. Also, the performance goal orientation scores are higher than the learning goal orientation scores.

Table 6 illustrates the MANOVA results which include the comparison of the scores for intelligence perception and goal orientation, grouped by class level. 
Table 6. MANOVA Results which show the Comparison of Total Scores of University Students' Intelligence Perception and Goal Orientation Features According to Class Level Variable

\begin{tabular}{|c|c|c|c|c|c|}
\hline & Wilks' Lambda & F & Hypothesis df & Error df & P \\
\hline Intelligence Perception &, 026 & 1816,88 & 8 & 2808 &, 00 \\
Goal Orientation &, 063 & 1042,99 & 8 & 2808 &, 00 \\
\hline
\end{tabular}

Table 7. The results of Multivariate Analysis of Variance (MANOVA) for Each Perception of Intelligence and Goal Orientation in Terms of Class Level

\begin{tabular}{|c|c|c|c|c|c|c|}
\hline & Type III sum of Sm. & df & Mean Square & F & P & Difference \\
\hline Entity & 262,70 & 3 & 87,57 & 3,41 &, 01 & $2-3$ \\
\hline Error & 36002,48 & 1405 & 25,62 & & & $4-1,4-2$ \\
\hline Incremental & 177,86 & 3 & 59,28 & 3,14 &, 02 & \\
\hline Error & 26496,12 & 1405 & 18,85 & & & \\
\hline PGO & 26,908 & 3 & 8,96 & 1,51 &, 21 & \\
\hline Error & 8334,316 & 1405 & 5,93 & & &, 23 \\
\hline LGO & 25,296 & 3 & 8,43 & 1,41 & & \\
\hline Error & 8386,753 & 1405 & 5,96 & & & \\
\hline
\end{tabular}

Table 8. Arithmetic Mean and Standard Deviation Statistics of University Students' Intelligence Perception and Goal Orientation Features According to Gender Variable

\begin{tabular}{|c|c|c|c|c|c|c|c|c|}
\hline & \multicolumn{2}{|c|}{ Entity } & \multicolumn{2}{c|}{ Incremental } & \multicolumn{2}{c|}{ PGO } & \multicolumn{2}{c|}{ LGO } \\
\hline & $\bar{x}$ & $\mathrm{df}$ & $\bar{x}$ & $\mathrm{df}$ & $\bar{x}$ & $\mathrm{df}$ & $\bar{x}$ & $\mathrm{df}$ \\
\hline Female (N=831) & 16,04 & 4,94 & 11,77 & 4,23 & 7,70 & 2,42 & 5,16 & 2,41 \\
\hline Male (N=578) & 15,71 & 5,24 & 11,58 & 4,51 & 7,38 & 2,44 & 5,36 & 2,48 \\
\hline
\end{tabular}

When Table 6 is analyzed, the average scores for intelligence perception (Wilks' Lambda value, 026, $\mathrm{F}=1816,88, \mathrm{p}<.05$ ) and goal orientation (Wilks' Lambda value $, 063, \mathrm{~F}=1042,99, \mathrm{p}<.05)$ in terms of class level show a significant difference of , 05 level.

Table 7 illustrates the information about the comparative scores for the entity and incremental dimensions (two of the intelligence perception dimensions) and the comparative scores for the performance goal orientation and learning goal orientation (two of the goal orientation dimensions) by class level.

The $\mathrm{F}$ test is included in Table 7 to compare both the mean scores for the entity and incremental dimensions and the mean scores for the performance and learning goal orientation dimensions by class level. According to the MANOVA results, the mean scores of the entity and incremental dimensions show a statistically significant difference in terms of class level (respectively $\mathrm{F}=3,41 \mathrm{p}<.05$, $\mathrm{F}=3,14 \mathrm{p}<.05)$.

As the groups were homogeneous, the Tukey test was used in order to find out which class levels showed the difference in the mean entity and incremental scores of intelligence. According to the Tukey results, for the entity intelligence dimension, there is a significant difference between the 2 nd and 3rd grade classes -in the direction of the first-named department. For the incremental intelligence dimension, there is a significant difference between the 4 th and 1 st grade classes; 4th and 2nd grade classes - in the direction of the first-named department. The differences had statistical significance.

\subsection{What is the Goal Orientation and Perception of Intelligence of University Students Based on Their Gender?}

The third problem of the study is "What are the features of intelligence perceptions and goal orientation of university students according to gender variable?" and the descriptive scores related to this question are given in Table- 8 .

When comparing the perception of intelligence scores in terms of gender, the entity scores are higher than the incremental scores. Also, the performance goal orientation scores are higher than the learning goal orientation scores.

Table 9 illustrates the information about both the comparative scores for the entity and incremental dimensions (two of the intelligence perception dimensions) and the comparative scores for the performance goal orientation and learning goal orientation (two of the goal orientation dimensions) by gender. 
Table 9. The results of Multivariate Analysis of Variance (MANOVA) for Each Perception of Intelligence and Goal Orientation in Terms of Gender

\begin{tabular}{|c|c|c|c|c|c|c|}
\hline & Type III sum of Sm. & df & Mean Square & F & P & Difference \\
\hline Entity & 36,851 & 1 & 36,85 & 1,43 &, 23 & \\
\hline Error & 36228,33 & 1407 & 25,74 & & & \\
\hline Incremental & 11,80 & 1 & 11,80 &, 62 &, 43 & \\
\hline Error & 26662,18 & 1407 & 18,95 & & & f-m \\
\hline PGO & 34,10 & 1 & 34,10 & 5,76 &, 01 & \\
\hline Error & 8327,12 & 1407 & 5,91 & & & \\
\hline LGO & 12,87 & 1 & 12,87 & 2,15 & & \\
\hline Error & 8399,17 & 1407 & 5,97 & & & \\
\hline
\end{tabular}

Due to the number of categories under three, the LSD test was used in order to find out which gender showed the difference in the mean performance goal orientation dimension. When the performance goal orientation scores were taken into account, a significant difference was found in favour of females.

\subsection{What is the Relationship between Goal orientation and Perception of Intelligence of University Students?}

The fourth problem of the study is "Are there any correlation between features of intelligence perceptions and goal orientation of university students?" In this context, the Pearson Product Moment Correlation Coefficient test was used to determine the relationship features of intelligence perceptions and goal orientation of university students, and the data related to this question are given in Table-10.

Table 10. Correlation between features of intelligence perceptions and goal orientation of university students

\begin{tabular}{|c|c|c|c|c|}
\hline Sub Dimension & Entity & Incremental & PGO & LGO \\
\hline Entity & - &,$- 53^{* *}$ &, $18^{* *}$ &,- 02 \\
\hline Incremental & - & - &, 00 &, $12^{* *}$ \\
\hline PGO & - & - & - &,- 03 \\
\hline LGO & - & - & - & - \\
\hline
\end{tabular}

$* * \mathrm{p}<.01$

When examining Table 10, a medium-level negative correlation was found between the entity dimension and the incremental dimension. But, a low-level positive correlation was found between the entity dimension and performance goal dimension. Also, a low-level positive correlation was found between the incremental dimension and learning goal orientation.

\section{Conclusions and Discussion}

The findings of the study reveal that on average, the students scored more highly in relation to entity intelligence theory (fixed mindsets) than to incremental intelligence theory (growth mindsets), with some variation between academic disciplines. This finding is consistent with that of another recent Turkish study [2]. A possible reason for this result might be the cultural beliefs on intelligence. In Turkish culture students are being stereotyped based on their high-stakes exam scores which mostly related on math and science. Students who have high scores on those tests are smart and others are not. Most people believe that smart kids are born that way and if your kids don't have it there is nothing to do. These believes shape students' mind throughout the educational journey. Students need to be taught that intelligence is malleable.

A further finding of the present study is that the average entity and incremental theory scores are significantly different for students in different years: second year students had higher entity scores than third year students; fourth year students were found to have significantly higher incremental scores than first and second years. This suggests that early in their higher-education experience, these students tend to believe that intelligence cannot be changed, but that some later change their perceptions and come to believe that it is malleable. This finding supports those of others who have gathered evidence of development and change in student teachers' beliefs as their training progresses [44] ; [45].

In addition, on average the students appeared to be more likely to have a performance orientation than a learning orientation. This suggests that the students' perception about intelligence may shape their learning behaviour. The study also found that, on average, female students' scores on performance orientation measures were significantly higher than those of male students. Some studies have found similar results [46]; however most of the international research indicates that female students tend to be learning- oriented while male students tend to be performance-oriented [47]; [48]; [49]. One possible factor which accounted for the higher scores on performance orientation of female students might be the result of gender stereotype in the traditional Turkish culture. These stereotypes generally are negative for females since males have an unequal mastery positions over females. In Turkish culture males are dominant figures and females usually need to improve themselves for being capable of doing anything. For this reason they have to perform higher than males. 
The present study also confirms that there is a positively significant relationship between the average entity theory and performance orientation scores. In addition, a moderately positive significant relationship between the average incremental theory and learning orientation scores was found. These findings support previous studies which found significant relationships between perception of intelligence and goal orientation [20]; [1]; [4]; [21]; [15]; [23]; [10]; [13]; [24]; [19]; [22].

While this last finding is consistent with international findings, the findings on student teacher beliefs in the Turkish context are not consistent with the findings about similar students in other countries: student teachers from the US have been found to be more likely to hold the view that intelligence is malleable rather than that it is fixed [50]; [30]. The student teachers at a UK university were also found to hold beliefs broadly consistent with incremental theory, though those of East Asian were less likely to do so [51]. Fruitful areas for further research might therefore be:

- to explore further cultural and national variations in student teachers' beliefs about intelligence

- to seek to understand how such beliefs are formed in different cultural contexts

- to explore further gender variations in learning orientation in different cultural contexts

Further studies of the beliefs which underlie views about both goal orientation and views about intelligence whole lead to increase understanding about the mindset which creates the continual need to validate, rather than the desire to learn [1].

The findings of this study have significant policy implications for Turkish teacher education programmes. The effect of teachers' beliefs about intelligence on their pupils has been well documented [26]; [27]. For example, giving students performance-related praise encourages students to think that their intelligence and abilities are fixed, and furthermore encourages them to avoid challenging tasks and to lose confidence and motivation when the task becomes hard. It affects negatively their response to difficult problems. Conversely, giving students praise for process (such as praise for effort or strategy) encourages students to view their intelligence and abilities as malleable, increases their confidence and motivation, and encourages them to seek out and thrive on challenge [25]. Therefore, it is recommended that early in their course of study, student teachers should be introduced to Dweck's mindset theory [1] and encouraged to reflect on their own beliefs and learning behaviours and those of their pupils. Asking student teachers to explore different metaphors about teaching and learning is suggested as one useful methodology, both for throwing light on the students' implicit beliefs, and for supporting change [52]; [53].

Moreover, teacher education programmes could be re-designed to include the initial identification of students' beliefs about intelligence and their learning orientation. Students who have fixed views of intelligence and a performance orientation could be offered an enhanced level of support; however all student teachers should be encouraged to adopt and develop a teaching style which fosters a learning orientation through (for example) the types of classroom language and feedback used, and the attitude to challenge and effort promoted [18]. In particular, given the demonstrable value of high quality feedback strategies and the role of metacognition in learning (summarised in Hattie [18]), teacher trainees should be shown how to teach their pupils to think explicitly about their thinking, and learn about how best they learn.

\section{Acknowledgements}

This study was presented at the "X. European Conference on Social and Behavioural Sciences (ECSBS 2016)".

\section{REFERENCES}

[1] Dweck, C. S. (2000). Self-Theories: Their role in motivation, personality, and development. Philadelphia: Psychology Press.

[2] İlhan Beyaztaş, D.\& Hymer, B. (2016). An analysis of Turkish students perception of intelligence from primary school to university. Gifted Education International, doi: 10.1177/0261429416649041

[3] Dweck, C.S. \& Elliott, E.S. (1983). Achievement motivation. In P. Mussen and E. M. Hetherington (Eds.), Handbook child psychology (pp. 643-693). New York: Wiley.

[4] Dweck, C. S. \& Leggett, E. L. (1988). A social-cognitive approach to motivation and personality. Psychological Review, $95,256-273$

[5] Grant, H. \& Dweck, C. S. (2003). Clarifying achievement goals and their impact. Journal of Personality and Social Psychology, 85(3), 541-553. doi:10.1037/0022-3514.85.3.541

[6] Nicholls, J. G. (1984). Achievement motivation: Conceptions of ability, subjective experience, task choice, and performance. Psychological Review, 91, 328-346.

[7] Ames, C. (1992). Classrooms: Goals, structures, and student motivation. Journal of Educational Psychology, 84, 261-271.

[8] Elliot, A. J., \& Harackiewicz, J. M. (1996). Approach and avoidance achievement goals and intrinsic motivation: A mediational analysis. Journal of Personality and Social Psychology, 70, 461-475.

[9] Senko, C., \& Hulleman, C. S. (2013). The role of goal attainment expectancies in achievement goal pursuit. Journal of Educational Psychology, 105, 504-521.

[10] Roedel, T. D., \& Schraw, G. (1995). Beliefs about intelligence and academic goals. Contemporary Educational Psychology, 20, 464-468.

[11] Gul, F., \& Shehzad, S. (2012). Relationship between metacognition, goal orientation and academic achievement. 
Procedia Social and Behavioral Sciences, 47, 1864-1868. http://dx.doi.org/10.1016/j.sbspro.2012.06.914

[12] Wolters, C. A., Yu, S. L., \& Pintrich, P. R. (1996). The relation between goal orientation and students' motivational beliefs and self-regulated learning. Learning and Individual Differences, 8 (3), 211-238.

[13] Blackwell, L. S., Trzesniewski, K. H., \& Dweck, C. S. (2007). Implicit theories of intelligence predict achievement across transition: A longitudinal study and an intervention. Child Development, 78(1), 246-263.

[14] Chen, W-W. \& Wong, Y-L. (2015). Chinese mindset: theories of intelligence, goal orientation and academic achievement in Hong Kong students. Educational Psychology, 35(6), 714-725.

[15] Dupeyrat, C. \& Mariné, C. (2005). Implicit theories of intelligence, goal orientation, cognitive engagement, and achievement: A test of Dweck's model returning to school adults. Contemporary Educational Psychology, 30, 43-59.

[16] Cadwallader, S.M. (2009). The Implicit Theories of Intelligence of English Adolescents Identified as Gifted and Talented. Unpublieshed Doctoral Dissertation, University of Warwick

[17] Yeager DS, Paunesku D, Walton GM, et al. (2013) How can we instill productive mindsets at scale? A review of the evidence and an initial R\&D agenda. White paper prepared for the White House meeting on Excellence in education: The importance of academic mindsets. May 10, 2013.

[18] Hymer, B. \& Gershon, M. (2014). Growth Mindset Pocketbook. Alresford: Teachers' Pocketbooks

[19] Cury, F., Elliot, A., Da Fonseca, D. \& Moller, A.C. (2006). The Social Cognitive Model of Achievement Motivation and the 2x2 Achievement Goal Framework. Journal of Personality and Social Psychology, 90, 666-679.

[20] Dweck, C. S. (1986). Motivational processes affecting learning. American Psychologist, 41(10), 1040-1048.

[21] Elliott, E. S. \& Dweck, C. S. (1988). Goals: An approach to motivation and achievement. Journal of Personality and Social Psychology, 54, 5-12.

[22] Siegle, D, Rubenstein, L. D., Pollard, E., \& Romey, E. (2010). Exploring the Relationship of College Freshmen Honors Students' Effort and Ability Attribution, Interest, and Implicit Theory of Intelligence With Perceived Ability. Gifted Child Quarterly 54(2) 92-101.

[23] Stipek, D. \& Gralinski, H. (1996). Children's theories of intelligence and school performance. Journal of Educational Psychology, 88, 711-723.

[24] Aronson, J., Fried, C. \& Good, C. (2002). Reducing the Effects of Stereotype Threat on African American College Students by Shaping Theories of Intelligence. Journal of Experimental Social Psychology, 38, 113-125.

[25] Dweck, C.S. (2008). Mindsets and Math/Science Achievement. Report prepared for the Carnegie Corporation of $\mathrm{New}$ York-Institute for Advanced Study Commission on Mathematics and Science Education Carnegie Corporation: New York. Retrieved from file://C:/Users/user/Downloads/mindsets,\%20gender\%20diff erences $\% 20(1)$.pdf
[26] Lynott, D. J. \& Wolfolk, A. E. (1994). Teachers' implicit theories of intelligence and their educational goals. Journal of Research and Development in Education, 27 (Summer), 253-264.

[27] Lee, K. (1996). A study of teacher responses based on their conceptions of intelligence. Journal of Classroom Interaction, 31(Summer), 1-12.

[28] Schmidt, J. A., Shumow, L. \& Kackar-Cam, H. (2015). Exploring teacher effects for mindset intervention outcomes in seventh-grade science classes. Middle Grades Research Journal, 10(2), 17-32.

[29] Swann, W. B. \& Snyder, M. (1980). On Translating beliefs into action: theories of ability and their application in an instructional setting. Journal of Personality and Social Psychology, 38(6), 879-88.

[30] Gutshall, C. A. (2014) 'Pre-Service teacher' mindset beliefs about student ability" Electronic Journal of Research in Educational Psychology, 12(3), pp.785-802

[31] Hambleton R. K. \& Patsula L (1999). Increasing the validity of adapted tests: myths to be avoided and guidelines for improving test adaptation practices. Journal of Applied Testing Technology 1(1): 1-30.

[32] Kline, P. (1994). An easy guide to factor analysis. New York: Routledge.

[33] Comrey, A. L. (1973). A first course in factor analysis. Academic Press: New York, NY.

[34] Turoff, M. (1971). Delphi and its potential impact on information systems, AFIPS Conference Proceedings, 39 (971) Montvale: AFIPS press. Fall Joint Computer Conference 39: 317-326.

[35] Turoff M and Helmer O (2002) The Delphi method techniques and applications. Available at:

http://is.njit.edu/pubs/delphibook/delphibook.pdf （accessed 31 January 2016).

[36] Uhl NP (1990) Delphi technique In: Walberg HJ and Haertel GD (eds) The International Encyclopedia of Educational Evaluation. Oxford: Pergamon Press.

[37] Pallant, J. (2005). SPSS Survival Manual: A step by step guide to data analysis using SPSS for Windows (Versions 12). Sydney: Allen \& Unwin

[38] Widaman, K. F., Little, T. D., Preacher, K. J., \& Sawalani, G. M. (2011). On creating and using short forms of scales in secondary research. In K. H. Trzesniewski, M. B. Donnellan, \& R. E. Lucas (Eds.), Secondary data analysis: An introduction for psychologists. Washington, DC: American Psychological Association.

[39] Briggs, S. R. ve Cheek, J. M. (1986). The role of factor analysis in the development and evaluation of personality scales. Journal of Personality, 54(1), 106-148.

[40] Kline, R. B. (2005). Principles and Practice of Structural Equation Modeling. (Second Edition). NY: Guilford Publications, Inc.

[41] Tabachnick B. G. and Fidel, L. S. (2001). Using Multivariate Statistics. (Fourth Edition). MA: Allyn \& Bacon, Inc.

[42] Brown, T. A. (2006). Confirmatory Factor Analysis for Applied Research. (First Edition). NY: Guilford Publications, Inc. 
[43] Jöreskog, K. G. ve Sörbom, D. (1993). LISREL 8: Structural Eguation Modeling with the Simplis Command Language. USA: Scientific Software international, Inc.

[44] Cabaroglu, N. \& Roberts, J. (2000). Development in student teachers' pre-existing beliefs during a 1-year PGCE programme. System 28, 387- 402

[45] Nettle, E.B. (1998). Stability and change in the beliefs of student teachers during practice teaching. Teaching and teacher education, 14(2), 193-204.

[46] Chan, K., Lai, P.Y.M., Leung, M.T., \& Moore, P.J. (2002). Hong Kong preservice teachers' achievement goal orientations-Are they related to their gender and electives. Hong Kong Teachers' Centre Journal, 1, 20-31.

[47] Ablard, K. E., \& Mills, C. J. (1996). Implicit theories of intelligence and self- perception of academically talented adolescents and children. Journal of Youth and Adolescence, $25,137-148$.

[48] Kenney-Benson, G. A., Pomerantz, E. M., Ryan, A. M., \& Patrick, H. (2006). Sex differences in math performance: The role of children's approach to schoolwork. Developmental Psychology, 42(1), 11-26.
[49] Shim, S. S., Cho, Y., \& Cassady, J. (2013). Goal structures: The role of teachers' achievement goals and theories of intelligence. The Journal of Experimental Education, 81(1), 84- 104.

[50] Jones, B.D., Bryant, L.H., Snyder, J.D. \& Malone, D. (2012). Preservice and inservice teachers' implicit theories of intelligence. Teacher Education Quarterly, 39(2), pp.87-101.

[51] Asbury, Kathryn; Klassen, Rob; Bowyer-Crane, Claudine Anne; Kyriacou, Chris; Nash, Poppy. (2015). National differences in mindset among students who plan to be teachers. International Journal of School and Educational Psychology, $4(3), 158-164$

[52] Saban, A. (2010). "Prospective teachers' metaphorical conceptualizations of learner". Teaching and Teacher Education, 26, 290-305

[53] Löfström, E. \& Poom-Valickis, K.. (2013). Beliefs about teaching: Persistent or malleable? A longitudinal study of prospective student teachers' beliefs. Teaching and Teacher Education, 35, 104-113.

[54] Hattie, J. (2009). Visible Learning - A synthesis of over 800 meta-analyses relating to achievement. Abingdon: Routledge 